\title{
Efficacy of high-dose teneligliptin, a dipeptidyl peptidase-4 inhibitor, for glycemic parameters in patients with type 2 diabetes estimated with continuous glucose monitoring: A pilot study
}

\author{
Ichiro Abe $^{1 *}$, Kaoru Sugimoto ${ }^{1}$, Kaori Takeshita ${ }^{1}$, Midori Minezaki ${ }^{1}$, Yuki Fujimura ${ }^{1}$, Monami Koga ${ }^{1}$, Saori Kuramoto ${ }^{1}$, Tadachika Kudo \\ and Kunihisa Kobayashi ${ }^{1}$ \\ ${ }^{1}$ Department of Endocrinology and Diabetes Mellitus, Fukuoka University Chikushi Hospital, Chikushino, Fukuoka, Japan
}

\begin{abstract}
Background: Few studies have focused on the "glucose-normalizing effects" of high and standard doses of dipeptidyl peptidase-4 (DPP-4) inhibitors evaluated using continuous glucose monitoring (CGM). Teneligliptin is a DPP-4 inhibitor licensed in Japan for administration at standard (20 mg/day) and high (40 mg/day) doses to treat type 2 diabetes mellitus. However, little is known about its effects on the "quality" of glucose control or plasma glucose fluctuation, including factors such as postprandial glucose levels and frequency of hypoglycemia. We used CGM to study the efficacy of high-dose teneligliptin for the treatment of diabetic patients.

Materials and methods: Mean amplitude of glycemic excursions (MAGE), and mean, minimum, maximum, and standard deviation (SD) of glucose concentrations were measured by CGM in ten hospitalized individuals with type 2 diabetes mellitus.

Results: Compared with effects of standard-dose teneligliptin, MAGE, SD, and maximum glucose concentrations were significantly reduced by high-dose teneligliptin $(P<0.01)$. There was no significant difference in mean glucose concentrations, whereas minimum glucose concentrations were significantly increased by high-dose teneligliptin $(P=0.0314)$.
\end{abstract}

Conclusion: High-dose teneligliptin decreases hypoglycemia and may provide good "quality" of glucose control, thereby reducing the risk of diabetic complications and improving the patients' quality of life.

\section{Introduction}

Incretins, including glucagon-like peptide-1 (GLP-1) and glucosedependent insulinotropic polypeptide (GIP), exert antidiabetic activities by stimulating insulin secretion and inhibiting postprandial glucagon secretion in a manner dependent on plasma glucose levels [1]. Dipeptidyl peptidase-4 (DPP-4) inactivates incretins by hydrolysis; thus, DPP-4 inhibitors stimulate insulin secretion and inhibit glucagon secretion leading to reduced glucose levels without hypoglycemia [2]. In addition, DPP-4 inhibitors have been reported to prevent hypoglycemia by enhancing glucagon secretion during the hypoglycemic period [3]. Teneligliptin has been reported to be a potent, long-lasting DPP-4 inhibitor [4] and is licensed in Japan for administration at standard (20 $\mathrm{mg}$ /day) and high (40 mg/day) doses for glycemic control [5]. However, little is known about effects of high-dose teneligliptin on plasma glucose fluctuation, including the frequency of postprandial glucose increase and hypoglycemia. In this study, we used continuous glucose monitoring (CGM) to assess whether high-dose teneligliptin is superior to the standard dose in terms of the "quality" of glucose control.

\section{Materials and methods}

\section{Materials}

We recruited ten individuals with type 2 diabetes mellitus (21-81 years) hospitalized at Fukuoka University Chikushi Hospital from
April 2014 to June 2016. We have exclusion criteria of this study. Patients who are or might have been pregnant, those with severe liver dysfunction (including liver cirrhosis), and those who have or had any malignancy were excluded, and all participants provided written informed consent to inclusion in this study, which was approved by the Ethics Review Committee of Fukuoka University Chikushi Hospital (Japan). Participant characteristics are shown in Table 1.

\section{Methods}

The Medtronic iPro 2 CGM system (Medtronic, Northridge, CA, USA) was used for continuous glucose monitoring with Medtronic Enlite $^{\mathrm{Tx}}$ glucose sensors (Medtronic) placed on the abdomen according to the manufacturer's instructions. Patients were fitted with the CGM device (Day 0) and were started on the standard dose $(20 \mathrm{mg} /$ day) of teneligliptin for 2 days (Days 1 and 2) followed by high-dose $(40 \mathrm{mg} /$ day) teneligliptin for an additional 2 days (Days 3 and 4 ) continuously.

Correspondence to: Ichiro Abe, Department of Endocrinology and Diabetes Mellitus, Fukuoka University Chikushi Hospital, 1-1-1 Zokumyoin, Chikushino, Fukuoka 818-8502, Japan, Tel: +81-92-921-1011; E-mail: abe1ro@fukuoka-u.ac.jp

Key words: continuous glucose monitoring, dipeptidyl peptidase-4 inhibitor, glucose fluctuation

Received: March 28, 2017; Accepted: April 26, 2017; Published: April 29, 2017 
Abe I (2017) Efficacy of high-dose teneligliptin, a dipeptidyl peptidase-4 inhibitor, for glycemic parameters in patients with type 2 diabetes estimated with continuous glucose monitoring: A pilot study

Table 1. Participant characteristics.

\begin{tabular}{|c|c|c|c|c|c|c|c|c|}
\hline No & Sex & $\begin{array}{l}\text { Age } \\
(y)\end{array}$ & $\begin{array}{l}\text { HbA1c } \\
(\%)\end{array}$ & BMI & $\begin{array}{c}\text { eGFR } \\
\left(\mathrm{ml} / \mathrm{min} / 1.73 \mathrm{~m}^{2}\right)\end{array}$ & $\begin{array}{c}\text { U-CPR } \\
(\mu \mathrm{g} / \mathrm{day})\end{array}$ & $\begin{array}{c}\text { Diabetic } \\
\text { complication }\end{array}$ & $\begin{array}{c}\text { Other diabetic } \\
\text { treatment }\end{array}$ \\
\hline 1 & M & 78 & 6.9 & 26.4 & 68.5 & 48.2 & none & none \\
\hline 2 & $\mathrm{~F}$ & 66 & 7.3 & 18.2 & 92.0 & 39.3 & $\begin{array}{l}\text { neuropathy } \\
\text { retinopathy }\end{array}$ & none \\
\hline 3 & M & 61 & 7.7 & 26.8 & 76.1 & 123.0 & none & dapagliflozin (5 mg/day) \\
\hline 4 & $\mathrm{~F}$ & 51 & 8.3 & 24.2 & 76.9 & 29.0 & none & metformin (500 mg/day) \\
\hline 5 & M & 21 & 11.7 & 24.8 & 139.1 & 82.3 & none & metformin $(1000 \mathrm{mg} /$ day $)$ \\
\hline 6 & $\mathrm{M}$ & 55 & 10.0 & 27.0 & 90.7 & 132.0 & none & metformin $(1000 \mathrm{mg} /$ day $)$ \\
\hline 7 & M & 69 & 9.7 & 23.4 & 84.3 & 50.2 & $\begin{array}{l}\text { neuropathy } \\
\text { nephropathy }\end{array}$ & $\begin{array}{c}\text { insulin (32 U/day) } \\
\text { metformin (500 mg/day) }\end{array}$ \\
\hline 8 & M & 81 & 9.4 & 20.1 & 43.7 & 21.8 & neuropathy & insulin (16 U/day) \\
\hline 9 & $\mathrm{~F}$ & 79 & 8.6 & 24.3 & 72.9 & 44.0 & neuropathy & insulin (15 U/day) \\
\hline 10 & $\mathrm{~F}$ & 63 & 9.2 & 24.8 & 71.1 & 47.6 & none & insulin (22 U/day) \\
\hline
\end{tabular}

HbA1c: hemoglobin A1c, BMI: body mass index, eGFR: estimated glomerular filtration rate, U-CPR: urinary C-peptide immunore activity

We used CGM data obtained on Days 2 and 4 for determining the mean, maximum, minimum, and standard deviation (SD) of glucose levels, and the mean amplitude of glycemic excursion (MAGE), which was calculated as the mean difference between consecutive blood glucose peaks and nadirs measured continuously by CGM, provided that the differences were greater than one SD of the mean glucose value as described previously [6]. During this period, diet, exercise or drugs were not changed.

\section{Statistical analysis}

Data were expressed as mean \pm SD or standard error of the mean (SEM). The statistical significance of differences between means was estimated by paired Student's $t$-test. Values of $P<0.05$ were considered to indicate statistical significance.

\section{Results}

Patients' glucose levels over 24 hours and glycemic parameters (MAGE, SD, and the mean, minimum and maximum glucose levels) measured using CGM are shown in Figure 1 and Table 2. Table 3 shows that the MAGEs were significantly lower during administration of highdose teneligliptin $(61.7 \pm 17.4 \mathrm{mg} / \mathrm{dl})$ compared with those measured during administration of the standard dose $(98.4 \pm 26.2 \mathrm{mg} / \mathrm{dl})(P=$ $0.0088)$. The $S D$ values of the glucose concentrations were significantly lower during administration of high-dose teneligliptin $(26.3 \pm 9.7$ $\mathrm{mg} / \mathrm{dl}$ ) compared with those measured during administration of the standard dose $(39.7 \pm 15.3 \mathrm{mg} / \mathrm{dl})(P=0.0027)$. Maximum glucose levels were significantly decreased by high-dose teneligliptin $(205.9 \pm$ $39.2 \mathrm{mg} / \mathrm{dl})$ compared with the effects of the standard dose $(244.7 \pm 55.5$ $\mathrm{mg} / \mathrm{dl})(P=0.0088)$. There was no significant difference in the effects of the two doses of teneligliptin on the mean glucose levels (high-dose teneligliptin: $147.1 \pm 22.3 \mathrm{mg} / \mathrm{dl}$ vs. standard-dose teneligliptin: 155.5 $\pm 35.3 \mathrm{mg} / \mathrm{dl}$ ). However, minimum glucose levels were significantly increased during administration of high-dose teneligliptin (103.9 \pm $12.4 \mathrm{mg} / \mathrm{dl}$ ) compared with those measured during administration of the standard dose $(91.2 \pm 13.4 \mathrm{mg} / \mathrm{dl})(P=0.0314)$.

\section{Discussion}

With the increasing prevalence of type 2 diabetes worldwide [7] comes an increase in the importance of preventing its complications [8]. Glucose homeostasis is controlled by both insulin resistance and the secretion of insulin and glucagon [9]. Persistent hyperglycemia leads to diabetic microangiopathies, such as neuropathy, nephropathy, and retinopathy. Furthermore, studies such as the DECODE (Diabetes Epidemiology: Collaborative Analysis of Diagnostic Criteria in
Table 2. Glycemic parameters of participants measured by continuous glucose monitoring.

\begin{tabular}{|c|c|c|c|c|c|}
\hline \multicolumn{6}{|c|}{ Standard dose of teneligliptin ( $20 \mathrm{mg} /$ day $)$} \\
\hline No & $\begin{array}{l}\text { minimum } \\
\text { glucose } \\
(\mathrm{mg} / \mathrm{dl})\end{array}$ & $\begin{array}{c}\text { maximum } \\
\text { glucose } \\
(\mathrm{mg} / \mathrm{dl})\end{array}$ & $\begin{array}{l}\text { MAGE } \\
\text { (mg/dl) }\end{array}$ & SD & $\begin{array}{c}\text { mean } \\
\text { glucose } \\
(\mathrm{mg} / \mathrm{dl})\end{array}$ \\
\hline 1 & 91 & 203 & 82.3 & 27 & 125 \\
\hline 2 & 78 & 211 & 70.3 & 30 & 138 \\
\hline 3 & 84 & 224 & 97.3 & 30 & 127 \\
\hline 4 & 97 & 193 & 89.3 & 29 & 133 \\
\hline 5 & 97 & 216 & 77.3 & 35 & 153 \\
\hline 6 & 80 & 185 & 57.0 & 21 & 130 \\
\hline 7 & 72 & 249 & 135.0 & 40 & 133 \\
\hline 8 & 114 & 363 & 132.3 & 65 & 239 \\
\hline 9 & 113 & 299 & 119.3 & 56 & 198 \\
\hline 10 & 86 & 304 & 124.0 & 64 & 173 \\
\hline \multicolumn{6}{|c|}{ High dose of teneligliptin $(40 \mathrm{mg} / \mathrm{day})$} \\
\hline No & $\begin{array}{l}\text { minimum } \\
\text { glucose } \\
(\mathrm{mg} / \mathrm{dl})\end{array}$ & $\begin{array}{c}\text { maximum } \\
\text { glucose } \\
(\mathrm{mg} / \mathrm{dl})\end{array}$ & $\begin{array}{l}\text { MAGE } \\
\text { (mg/dl) }\end{array}$ & SD & $\begin{array}{c}\text { mean } \\
\text { glucose } \\
(\mathrm{mg} / \mathrm{dl})\end{array}$ \\
\hline 1 & 82 & 175 & 54.3 & 19 & 123 \\
\hline 2 & 100 & 221 & 68.0 & 29 & 147 \\
\hline 3 & 107 & 189 & 57.7 & 21 & 130 \\
\hline 4 & 100 & 196 & 74.6 & 27 & 131 \\
\hline 5 & 102 & 195 & 62.3 & 24 & 143 \\
\hline 6 & 89 & 141 & 21.0 & 14 & 119 \\
\hline 7 & 121 & 170 & 34.0 & 13 & 145 \\
\hline 8 & 119 & 247 & 76.0 & 39 & 179 \\
\hline 9 & 120 & 255 & 69.3 & 39 & 188 \\
\hline 10 & 99 & 270 & 89.3 & 44 & 166 \\
\hline
\end{tabular}

MAGE: mean amplitude of glycemic excursion, SD: standard deviation.

Europe) study showed that postprandial hyperglycemia correlates with the occurrence of macroangiopathy [10]. The ACCORD (Action to Control Cardiovascular Risk in Diabetes) and ADVANCE (Action in Diabetes and Vascular Disease: Preterax and Diamicron MR Controlled Evaluation) studies showed that severe hypoglycemia is a risk factor for microangiopathy, cardiovascular disease, and mortality [11,12]. It is also reported that large glucose fluctuations cause oxidative stress, thereby leading to endothelial cell injury [13]. DPP-4 inhibitors are known to decrease hyperglycemia by stimulating insulin secretion and inhibiting glucagon secretion, owing to an increase in GLP-1 [14]. And it has been reported that DPP-4 inhibitors raise glucagon levels in the hypoglycemic state owing to an increase in GIP; thus, providing the capacity to prevent hypoglycemia [15]. DPP-4 inhibitors have also been reported to reduce MAGEs [16]. For these reasons, DPP-4 inhibitors are expected to prevent diabetic complications. Teneligliptin is a DPP- 
Abe I (2017) Efficacy of high-dose teneligliptin, a dipeptidyl peptidase-4 inhibitor, for glycemic parameters in patients with type 2 diabetes estimated with continuous glucose monitoring: A pilot study

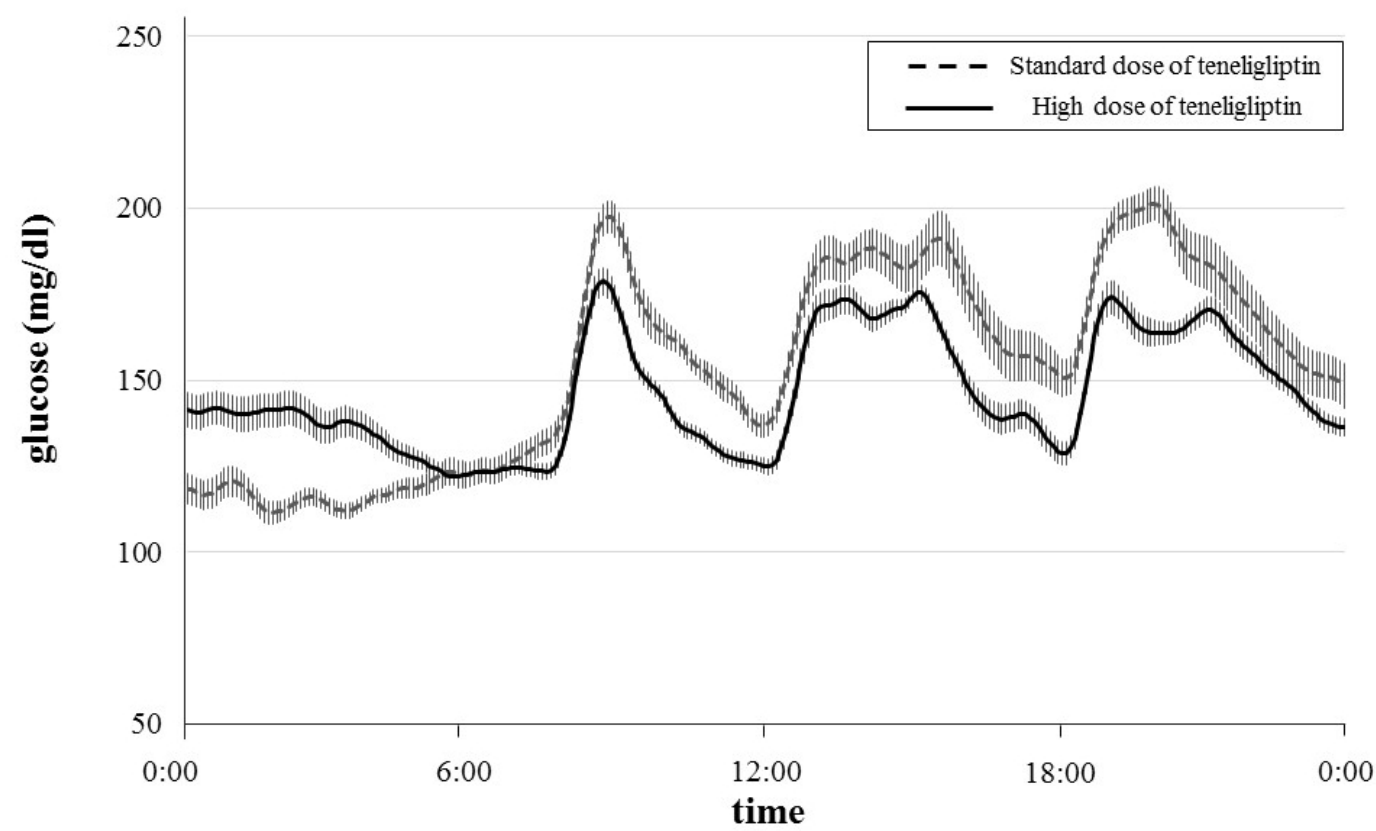

Figure 1. Changes in glucose level over 24 hours treated with standard dose and high dose of teneligliptin measured by CGM. Data are the mean \pm standard error of the mean (SEM).

Table 3. Analysis of glycemic parameters of participants measured by continuous glucose monitoring.

\begin{tabular}{|c|c|c|c|}
\hline & $\begin{array}{c}\text { Standard dose of } \\
\text { teneligliptin } \\
\text { (20 mg/day) }\end{array}$ & $\begin{array}{c}\text { High dose of } \\
\text { teneligliptin } \\
\mathbf{( 4 0 ~ m g / d a y ) ~}\end{array}$ & $\boldsymbol{p}$ \\
\hline $\begin{array}{c}\text { minimum glucose } \\
\text { (mg/dl) }\end{array}$ & $91.2 \pm 13.5$ & $103.9 \pm 12.4$ & $0.0314^{*}$ \\
\hline $\begin{array}{c}\text { maximum glucose } \\
\text { (mg/d) }\end{array}$ & $244.7 \pm 55.5$ & $205.9 \pm 39.2$ & $0.0088^{*}$ \\
\hline $\begin{array}{c}\text { MAGE } \\
\text { (mg/dl) }\end{array}$ & $98.4 \pm 26.2$ & $61.7 \pm 17.4$ & $0.0024^{*}$ \\
\hline SD & $39.7 \pm 15.3$ & $26.3 \pm 9.7$ & $0.0027^{*}$ \\
\hline mean glucose & $155.5 \pm 35.3$ & $147.1 \pm 22.3$ & 0.2148 \\
\hline (mg/d) & & & \\
\hline
\end{tabular}

Data are expressed as mean \pm standard deviation (SD). The significance of differences between means was estimated by paired Student's $t$-test. Values of $P<0.05$ were considered to indicate statistical significance $(*)$.

4 inhibitor that has been shown to significantly improve 24 -h blood glucose control in Japanese patients with type 2 diabetes [17]. In Japan, teneligliptin is licensed for administration at standard $(20 \mathrm{mg} /$ day $)$ and high $(40 \mathrm{mg} /$ day) doses; however, a previous study showed that there was no statistically significant difference in the effects on HbAlc levels mediated by the standard dose ( $-0.9 \%$ vs. placebo) and the high dose of teneligliptin ( $-1.0 \%$ vs. placebo) [18]. In contrast to this, our results using CGM revealed a dose-dependent improvement in the effects of teneligliptin on MAGE, SD, and maximum of glucose levels. In addition, high-dose teneligliptin raised the minimum glucose levels significantly compared with the effects of the standard dose. These data indicate that high-dose teneligliptin may prevent a hypoglycemic event, not only reducing the risk of diabetic complications but also improving the safety and quality of life (QOL) of patients with type 2 diabetes.

In conclusion, we recommend that high-dose teneligliptin should be a potent treatment alternative for patients with type 2 diabetes to attain good "quality" of glucose control and reduce the risk of diabetic complications. It should be noted that the limitations of our study include the small number of cases and the short duration of the period of investigation. Thus, further randomized control studies including larger numbers of cases, with longer-term monitoring are required to confirm the beneficial effects of high-dose teneligliptin and other DPP4 inhibitors in patients with type 2 diabetes.

\section{Conflict of interest}

The authors declare that there is no conflict of interests regarding the publication of this paper.

\section{References}

1. Drucker DJ (2007) The role of gut hormones in glucose homeostasis. J Clin Invest 117: 24-32. [Crossref]

2. Barnett A (2006) DPP-4 inhibitors and their potential role in the management of type 2 diabetes. Int J Clin Pract 60: 1454-1470. [Crossref]

3. Ahrén B, Schweizer A, Dejager S, Dunning BE, Nilsson PM, et al. (2009) Vildagliptin enhances islet responsiveness to both hyper- and hypoglycemia in patients with type 2 diabetes. J Clin Endocrinol Metab 94: 1236-1243.

4. Yoshida T, Akahoshi F, Sakashita H, Kitajima H, Nakamura M, et al. (2012) Discovery and preclinical profile of teneligliptin (3-[(2S,4S)-4-[4-(3-methyl-1-phenyl-1Hpyrazol-5-yl)piperazin-1-yl]pyrrolidin-2-ylcarbonyl]thiazolidine): a highly potent, selective, long-lasting and orally active dipeptidyl peptidase IV inhibitor for the treatment of type 2 diabetes. Bioorg Med Chem 20: 5705-5719.

5. Otsuki H, Kosaka T, Nakamura K, Shimomura F, Kuwahara Y, et al. (2014) Safety and efficacy of teneligliptin: a novel DPP-4 inhibitor for hemodialysis patients with type 2 diabetes. Int Urol Nephrol 46: 427-432.

6. Service FJ, Molnar GD, Rosevear JW, Ackerman E, Gatewood LC, et al. (1970) Mean amplitude of glycemic excursions, a measure of diabetic instability. Diabetes 19: 644655. [Crossref]

7. Zimmet P, Alberti KG, Shaw J (2001) Global and societal implications of the diabetes epidemic. Nature 414: 782-787. [Crossref]

8. Edelman SV (1998) Importance of glucose control. Med Clin North Am 82: 665-687. [Crossref]

9. Virally M, Blicklé JF, Girard J, Halimi S, Simon D, et al. (2007) Type 2 diabetes mellitus: epidemiology, pathophysiology, unmet needs and therapeutical perspectives. Diabetes Metab 33: 231-244.

10. The DECODE study group on behalf of the European Diabetes Epidemiology Group (1999) Glucose tolerance and mortality: comparison of WHO and American Diabetic Association diagnostic criteria. Lancet 354: 617-621. 
Abe I (2017) Efficacy of high-dose teneligliptin, a dipeptidyl peptidase-4 inhibitor, for glycemic parameters in patients with type 2 diabetes estimated with continuous glucose monitoring: A pilot study

11. Action to Control Cardiovascular Risk in Diabetes Study Group, Gerstein HC, Miller ME, Byington RP, Goff DC Jr, et al. (2008) Effects of intensive glucose lowering in type 2 diabetes. $N$ Engl J Med 358: 2545-2559.

12. Zoungas S, Patel A, Chalmers J, de Galan BE, Li Q, et al. (2010) Severe hypoglycemia and risks of vascular events and death. $N$ Engl J Med 363: 1410-1418. [Crossref]

13. Monnier L, Mas E, Ginet C, Michel F, Villon L, et al. (2006) Activation of oxidative stress by acute glucose fluctuations compared with sustained chronic hyperglycemia in patients with type 2 diabetes. JAMA 295: 1681-1687.

14. Lotfy M, Singh J, Rashed H, Tariq S, Zilahi E, et al. (2014) Mechanism of the beneficial and protective effects of exenatide in diabetic rats. J Endocrinol 220: 291304. [Crossref]
15. Malmgren S, Ahrén B (2015) DPP-4 inhibition contributes to the prevention of hypoglycaemia through a GIP-glucagon counterregulatory axis in mice. Diabetologia 58: 1091-1099.

16. Rizzo MR, Barbieri M, Marfella R, Paolisso G (2013) Response to Comment on: Rizzo et al. Reduction of oxidative stress and inflammation by blunting daily acute glucose fluctuations in patients with type 2 diabetes: role of dipeptidyl peptidase-IV inhibition. Diabetes Care 2012;35:2076-2082. Diabetes Care 36: e13. [Crossref]

17. Kishimoto M (2013) Teneligliptin: a DPP-4 inhibitor for the treatment of type 2 diabetes. Diabetes Metab Syndr Obes 6: 187-195. [Crossref]

18. Kadowaki T, Kondo K (2013) Efficacy, safety and dose-response relationship of teneligliptin, a dipeptidyl peptidase- 4 inhibitor, in Japanese patients with type 2 diabetes mellitus. Diabetes Obes Metab 15: 810-818.

Copyright: $@ 2017$ Abe I. This is an open-access article distributed under the terms of the Creative Commons Attribution License, which permits unrestricted use, distribution, and reproduction in any medium, provided the original author and source are credited. 